\title{
Why Follow All the Hoopla? Fake News Reporting on Social Media Platforms and Implications for Nation-State Building
}

\author{
Emmanuel K. Ngwainmbi* \\ Department of Communication Studies, University of North Carolina, Charlotte
}

*Corresponding Author: Emmanuel K. Ngwainmbi (Ph.D. /Prof.), Department of Communication Studies, University of North Carolina, Charlotte

\begin{abstract}
This paper argues that the seemingly unstoppable process of artificial news creation and content sharing has significant implications for the future of citizen journalism, news gathering and broadcasting around the world because fake news reporting has become a phenomenon among all age groups, cultures, communities, and social classes. While phony news sharing is more common in industrialized nations because of users' easy access to portable devices, those in emerging countries share news content on a massive scale, in part, because they do not have the resources to filter real news from fake news. The paper argues that users in the two regions (industrialized nations and poor or underdeveloped nations) may be less interested in working to decipher phony news content because it provides intrigue. Further, the paper presents examples of social injustice to support the claim that fake news reporting shared on social media can have significant implications on nation-building, particularly the socio-economic advancement of the nation. A case in point is that the increased incidents of content-sharing and content recycling in politically fragile states such as Cameroon, Libya, Burma, Iran, Indonesia, and China have been fueled by fears of government monitoring of social users. This paper uses the social interaction and uses and gratifications theories to examine the extent to which a networked, fast-paced news sharing society is indeed a global family; it also explains how fake news reporting can be a useful tool for community mobilization.
\end{abstract}

Keywords: Fake News, Content-Sharing, Social Media, Hoopla, News Reporting, Elections, NationBuilding, Issue Agenda Setting

\section{INTRODUCTION}

Easy access to social media platforms has created a tsunami of news and information flows to eager and unwitting audiences and markets alike around the world, with significant implications on users' consumption patterns and attitudes toward the topics shared. For better or worse social media has become a major driver on determining political outcomes, including in politically fragile nations, emerging communities, and industrialized regions. In recent years, social media platforms have become the new vox populi pushing away dictatorial regimes and fostering misinformation, fake news and related forms of free speech. Studies show social media use both as a post-truth engine and a hatemonger. Take the case of the 2017 Jakarta Gubernatorial Election in Indonesia - the world's most populous Muslim nation - where social media, while encouraging freedom of expression misleads ordinary citizens, emboldens people to hate and contributes to increasing polarization among citizens (Lim, 2017). Also, during the 2016 US Presidential Elections, fake news articles published on social media and widely distributed by mainstream media about the candidates' social life ushers in social media as an essential source of news. That style of communication suggests the democratic process itself is under threat. Through a nation-wide survey, Alcott and Gentzkow (2017) have found that of the false news stories appearing in online platforms three months before the election, those favoring then Presidential Candidate Trump have shared a total of 30 million times on Facebook, while those supporting his opponent Hilary Clinton were shared eight million times. That form of messaging suggests the democratic process itself may be under new threat.

The threat to democracy is per se not the primary concern of the growing number of young people in developing countries who are being radicalized by the news and information delivered primarily through Wassap and YouTube internet and influence decisions about the socio-political direction of their community. There is the desire by young people to access and utilize content transmitted through social media platforms, rather than rely on the news sources from the private press and state-run media outlets. 


\subsection{Contextual Definition}

Fake news is a type of yellow journalism or propaganda that consists of deliberate misinformation or hoaxes spread via traditional print and broadcast news media or online social media (Leonhardt \& Thompson, 2017). Fake news is written and published with the intent to mislead the public and damage an agency, entity, or person, and gain financially or politically (Hunt, 2916; Schlesinger, 2017). News creators use sensationalist, dishonest, or fabricated headlines to increase readership, sharing, and generate revenue.

'Nation-building' refers to the process of putting together a socially cohesive and mass-mediated process to shape and share knowledge and bring positive tangible change within that defined space. Here, the term 'building' typically associated with advancement-positive change-should not be construed as the norm. Rather, we argue that the notion of 'building' as a form of 'change' may eventually take a positive and productive or negative and destructive turn based on the values and beliefs of the majority. We also refer to three interrelated concepts of 'nation' advanced by Nadel (2005, p. 6). Nadal describes 'nation' as a set of common images and narratives that people share when they think of their nation and see themselves as citizens of that nation. For Deery (2012, p. 69), 'nation' is a sense people have of people of themselves, a territory with identified boundaries, an entity with its own governing body and communication mechanisms used within that space.

\subsection{Invoking the Social Interaction and Uses and Gratifications Theories}

Media content has a silver bullet shot from a media gun to penetrate a hapless audience (Anderson, 1988). Rather than the objects and events surrounding the actor being the thing that interprets the meaning of the scene, it is the actor that gives sense to the facts and artifacts, taking matters into any context the producer wishes to portrayl. In this case, the receiver (content consumer) is neither hapless nor passive but is controlled by the fake news creator whose actions are not governed by any structured cultural or social order but by personal worldviews. Consistent with this notion of mediated information generation and flow or what we merely perceive as hidden messages that influence the content receivers is Manuel Castell's (2010, 2004) views of social interaction. Castells has advanced the following worthwhile positions: media audiences participate actively in mediated communication; they construct meanings from the content they perceive. He further states that communication interaction involves actors' intent, receivers' interpretations, and message content. The purpose is not delivered during the communication process; instead, it is constructed within, and each communication act generates separate and potentially different sides of this construction.

Therefore, the social interaction theory determines the intentions of the media creator (e.g., producer, director, actor, writer), examines the media content (visual, verbal, musical, etc.), identify possible receiver interpretations, and assesses the potential effects on receivers. It provides a contrast with the selective exposure hypothesis of cognitive dissonance, reaffirming the power of the press while maintaining individual freedom, it is consistent with a "use and gratification" approach to television viewers' motives. Uses and gratifications theory (UGT) is an approach to understanding why and how people actively seek out specific media to satisfy particular needs. UGT is an audience-centered approach to understanding mass communication, 2and divergent positions on media impact on people and what people do with media.3 Given that scenario, we can visualize the potential impact of fake news on social media platforms on networked communities by revisiting Sandra Ball-Rokeach and Melvin DE Fleur (1989). The scholars contended that audiences depend on media information to meet needs and reach goals and that media systems interact with audiences to create obligations, interests, and motives in the person.

\section{Some EsSential Characteristics of FAKe NewS}

Fake news is a significant fabric in our society so much that significant world figures are publicly discussing its impact on the community. In the news media world today, media personnel are using communication technology to gather text, video, and images from around the globe with

\footnotetext{
${ }^{1}$ John Rey Abad, Social Action Theory, https://www.scribd.com/document/171827740/Social-Action-Theory

${ }^{2}$ Katz, Elihu (1959). "Mass Communications Research and the Study of Popular Culture: An Editorial Note on a Possible Future for this Journal." Departmental Papers (ASC): 1-6.

${ }^{3}$ Severin, Werner; Tankard, James (1997). Communication theories: Origins, methods, and uses in the mass media. Longman. ISBN 0801317037.
} 
unprecedented speed and different levels of editorial control. Technology allows news media to disseminate this information to audiences spread around the world. Because it is so easy to create a social platform, news monitoring agents cannot control the spread of inaccurate information. According to a report sponsored by the Shorenstein Center on Media, Politics and Public Policy and the Ash Center for Democratic Governance and Innovation at Harvard University, numerous information sources online leads people to rely heavily on heuristics and social cues. The reliance helps them determine the credibility of information and to shape their beliefs, which are in turn extremely difficult to correct or change. With a relatively small, but continuously changing number of sources that produce misinformation on social media, the task of applying real-time detection algorithms or delivering targeted socio-technical interventions is now more daunting than ever.

Fake stories can reach more people more quickly through social media than what old-fashioned reporting and bulk emails have accomplished accomplish in recent years. Unlike bulk emails that request services and mobilization or financial resources by the content (news) recipient, fake news typically aims to entertain the receiver. For example, digital publishing platforms like Facebook and Google have built ecosystems that reward clicks on website links and one of the most effective ways to drive traffic to a website is to entice readers with exciting content.

False news shocks and entertains, is worth sharing among the masses, and in some cases, it yields rewards. Macedonian teenagers became infamous after the press revealed they were behind several fake stories shared during the US election, mostly in support of Mr. Trump, earned thousands of dollars by getting thousands of clicks on articles they shared on Facebook (Olewe, 2017).

Fake news reporting also has double-edged nature. While it provides people the luxury of receiving news items within a short amount of time, they are inundated with a lot of tidbits and unable to process or assess its content. And all news shared on social media platforms cannot be verified. Aggression, intimidation and even death threats are among factors that can cause false news reporting in specific communities. Print journalists and writers in fascist regimes support the need to publish fake news for the public, particularly to caress the kind sentiments of the leaders of authoritarian regimes because the journalists' lives are continually under threat when they tell the truth. Even in some fragile states where the militia operates, journalists are forced to sugar coat or 'un-report' specific facts to avoid persecution. Velasco (2017, pp. 232-233) describes how drug trafficking organizations and government forces in Mexico masterminded the assassination or disappearance of 127 journalists from 2000-2015. Hence, press censorship and self-censorship exist in those states thereby taking democracy hostage. Such crude actions toward journalists obstruct press freedom and consequently endanger democratic reform.

Conversely, in open societies, false news reporting is much-needed entertainment. After having a stressful day at work or with other strenuous chores, people need something to help them unwind. Typically, however, it is assumed that individuals with lower (versus higher) levels of cognitive ability are less equipped to adjust to existing schemes and initial judgments when confronted with new, more reliable information. Information that is later proven to be incorrect has a more perseverant influence on social impressions for those individuals with lower (versus higher) levels of cognitive ability (De Keersmaecker \& Roets, 2017, p. 107).

It is more challenging to correct fake news because it is mass produced and spreads fast within a short time, and people don't take time to verify its content. Most readers do not find it necessary to crosscheck the entire source or review the posted opinions after they learn that such information was inaccurate, which leads to the abundance of fake news on social media platforms.

The false news gives the reader a sense of detachment from everyday reality or routine, a shirking of responsibilities, and a lack of concern for the values generally associated with 'getting on' in the world (Collier, 2013). As a social construct, fake news has a profound effect on interpersonal and thirdperson relationships and implications for counterfeit media literacy. Fake news has the elements of fiction and deception. Publications with an anonymous author; excessive exclamation points, capital letters, and misspellings; captions that begin with "This is NOT a hoax!"; "Breaking News," "Shared as received," or "forwarded as received" are among the alarming signs the content could be fake. Also, news published on dot.com sites without a URL and editorial staff and their contacts might not be trusted. Typically, readers and viewers lend themselves to psychological frailty. Next, fake news is 
capable of entertaining its users because it contains at least one of the following elements: gossip, hearsay, rumor, tittle-tattle, scandal.

\subsection{Frameworks for Detecting Fake News on Social Media Platforms}

The main reason for supporting phony news sharing culls from the notion that not all facts are useful for people and not all false information is inadequate for progress, including nation-building. We learn from human relationships by predicting, understanding, or changing behaviors, and the knowledge to either improve our lives or create more challenges. Within this framework, fake news is a form of misinformation that has the trappings of traditional broadcast and presumed to follow the editorial process and other standards associated with news reporting. It is nonpartisan, but a biased imposter content - a misleading and disingenuous use of information to frame an issue or an individual. Fake news is detected when official sources are impersonated with false, made-up sources (Wardle, 2017). As French philosopher Jean Baudrillard (1981) explained, simulation or fakery is determined when a copy exists without an original or when something exists with no relationship to reality. Satire or parody shared with no actual intention to harm has the potential to deceive. Indeed, the rapid growth of fake news has outpaced society's average level of media literacy, or the ability to access, analyze, evaluate and create media. And in the field of journalism, there is a growing concern that new news broadcasters use information creation and dissemination tools indiscriminately to share messages to different groups. That process undermines the integrity of the noble profession, although any attempt at preventing fake news generation and dissemination is bound to collide with many democratic values like freedom of speech.

Having the ability to identify fake news on any social media platform should limit its mitigating its effects on users in particular and society in general. Social media users should avoid forwarding messages to others without a byline or author's name as doing so only promulgates the spread of fake news. Persons taking part in a movement for change should attempt to authenticate statements such as "My sources say," "My informant at the Presidency has just told me that," or "Breaking News" that bloggers share on Facebook, and other social media platforms before sharing them. Their primary goal for using such catchy statements is to spur excitement. Social media groups with a common agenda should closely monitor bloggers, especially the well-known ones who frequently share 'pertinent' information; and note how many times the bloggers get their information right.

YouTube audiences should also examine the footage and headlines of any videos they receive to see if the information explains or complements the photo.

Recently, The Telegraph, a UK-based online newspaper, put together ways of detecting fake news from Facebook's tips for spotting false news. The reporters provide the following details:

- Be skeptical of headlines. The headlines of false news stories are often catchy and contain lots of capital letters and exclamation marks. If claims in the headline sound unbelievable, they may well be.

- Look closely at the URL. Many false news stories mimic authentic news sources by making small changes to the URL. You can go to the site to compare the URL to established sources.

- Check the source. Ensure the story comes from a source with a reputation for accuracy. If the story comes from a site you have not heard of, check their "About" section to learn more.

- Watch for unusual formatting. Many false news stories often contain spelling and grammar errors, as well as an awkward looking layout.

- Check the photos. Fake news stories often include manipulated images or videos. Sometimes the picture may be authentic but taken out of context. You can do an internet search for the model to find out its origin.

- Check the dates. Fake news stories may contain timelines that make no sense or event dates which are wrong or have been altered.

- Check the evidence. Check the author's sources to confirm they are accurate. Lack of evidence or reliance on unnamed experts may indicate false news.

- Look at other reports. If no other news source is reporting the same story, it could suggest that it is false. 
- Sometimes false news stories can be hard to distinguish from humorous articles. Check whether the source is known for parody and whether the story's details and tone suggest it may be just for fun.

- Some stories are intentionally false. Think critically about the stories that you read, and only share articles which you know to be credible. (Facebook's tips for spotting fake news (Telegraph Reporters, 2018).

\section{Why FAKe NeWS Reporting is CONVENTIONAL IN THE MEDIA}

Lies and inaccurate information are as old as humanity, but never before have they been so easily spread than through social media platforms. Branded initially as "disinformation" during the World War I and World War II "freak journalism" when influential US newspaper publishers turned up the heat to promote war with its adversaries. In his book, City Editor, published in 1934, Stanley Walker, City Editor of the New York Herald Tribune, asserted that newspapers had presented great fake stories. Fake news has since gained popularity in all communities around the world because it is shared across some social media platforms and through traditional broadcast media networks. The phony news even is discussed and dissected on real TV news shows. Editors of the mind-opening book titled Misinformation and Mass Audiences (2018) have explained that people do not share information just because it is false, they share it because it is exciting and receivers want it. Tweeting, retweeting, discussions in chatrooms about 'hot' issues of the day, e-blasts and forwarding content received have made fake news the most popular form of infotainment. When there is breaking news develops, people rely on social media for the latest updates. The use of social media in such situations comes with the caveat that new information released piecemeal may encourage rumors, many of which remain unverified long after their point of release (Zubiaga et al. 2016). We may recall a broadcast aired on March 26, 2017, on CBS, one the three largest networks in America. Scott Pelley was the Evening News correspondent and Michael Radetzky, Guy Campanile and Andrew Bast, producers. The report stated that con-artists had inserted fraudulent software that scans a user's social media account, resulting in millions of viewers getting fake stories (https://www.cbsnews.com/news/ how-fake-news-find-your-social-media-feeds . Retrieved Jan. 7, 2018).

Peer to peer sharing, especially on Facebook and Wassap, allows users to pass around stories like gossip while improving algorithms build filter bubbles that probably favor the spread of false, even outrageous stories. In a blog posted January 20, 2017, Ashley Rose Atkinson, a Marketing and Social Media Coordinator at White-Wilson Medical Center observed that the creators of fake news produce domain names similar to those on credible news sites, which surfers know and trust such as ABCNews.com.co versus ABCNew.go.com. Atkinson penned these thoughts:

"Creators of fake news... utilize outlandish headlines to draw readers to immediately sharing without investigating further and create fake authors with fake accolades that would put Robert Frost to shame. And these are just a few of the multiple techniques they employ to trick readers, reputable news organizations like CNN and Fox News, even international governments."

Mainstream news organizations validate the phenomenon of false news when they cite false news sources published elsewhere. For example, during the 2016 US Presidential Election when inaccurate stories were published online aimed at denigrating the image of the Democratic Presidential candidate, Hilary Clinton. According to CNN, Fox News and other American news networks, the stories were reportedly sponsored by the Republican candidate, Donald Trump. Tabloids in North America such as National Examiner, Globe, and The National Inquirer started in 1926 have been publishing false stories under the guise of "news" and selling their papers in supermarkets and online. Those tabloids have been in circulation for so many decades, which suggests that readers benefit from their content. The topics covered include sensational crime stories, astrology, celebrity gossip, and unverified television news. People who believe fake news tend to trust the channels used to disseminate the news. Aggressive social media campaign teams post hyper-partisan news on sites regarded as sources of information. Besides, there is no filtering mechanism can verify material published online.

\subsection{Psychological Factors: Misinformation as a Supportive Ingredient}

History has shown distraction to be an integral part of our being. Most psychologists rightly argue that sometimes the mind needs to get lost in a book of fiction, get distracted in a game, or let itself wander. 
Alan Brinkley, the author of Culture and Politics in the Great Depression, describes how escapism became the new, acceptable trend for dealing with the hardships created by the US stock market crash in 1929. Brinkley (2003) examines the genesis of the American dream, explaining how American people used persistence, empathy, rebellion, and community helped to cope with the Great Depression. Brinkley rightly points out that magazines, radio, and movies were aimed to help people mentally escape from the mass poverty and economic downturn, according to open access online sources. We have a genuine need to laugh at ourselves and others-we cherish moments, incidents, situations or dialogue that relieve us of our psychological burdens. Thus satire, lampoon, and language that ridicule a public figure are more likely to be accepted by the masses than facts. The increasing public interest in fake news is the latest sign of the evolution of our consciousness, given that we are facing more problems than ever in history. By most accounts, people in industrialized and developing nations, particularly politically fragile states might experience the most problems if they avoid self-gratifying incentives. Psychologists have found that eating, sleeping, exercise, and sexual intercourse can also become avenues of escapism when taken to extremes or out of proper context.

The excitement of reading fake news is not only a desirable, but it is also a necessity, a need that complements our modus operandi. It is so because we (human beings) cannot subsist on the scanty satisfaction we extort from reality (Freud \& Shipley, 1992). Our tendency to seek distraction from things we must endure validates fantasy as a necessary element in our lives. For those reasons, we biasedly argue that false information shared with more people creates a potentially harmful or positive impact on both the originator and the recipient and that it has a massive influence on their day-to-day dealings if shared on a long-term basis. What matters is that we depend on or need false information to stay connected with friends in the networked society and hence prolong relationships.

\subsection{Fake News Proliferation on Social Media platforms}

Social media is essential to storytelling, and news sharing in that content reaches the more people quicker an in a 'friendly' atmosphere. Social media tools are utilized across all traditional news outlets and on online resources alike to reach various audiences. Introduced in 1997, social media has not only allowed users to upload profiles, develop friendships with other users and create blogging sites as well as Facebook, tweeter accounts, it has succeeded in getting communities to participate in generating communication news and information locally and across national borders. Anyone with a small amount of money and I-Phone can now create and share content online as long as he/she accepts the terms of use, making it easy to disseminate unfiltered information. Depending on its nature and purpose, such information may be entertaining, distracting or may have devastating consequences to the sender and receiver(s).

Ultimately, information-sharing no matter what its origins, size, and purpose are intrinsic to understanding our nature. To exist, resist, or advance ourselves, we have to give, receive, retrieve, store and analyze information. As social animals, we have always relied on communication to strengthen, reconsider, or reject our relationships with others. As part of the data, new things are by physiological and psychological accounts more desirable than known things. The premise for such a view is that behavior patterns and simple rules govern human interactions. Stanford Communication Professor, Clifford Nass, argued that people remember negative things more strongly and in more detail than positive things (2012), meaning the brain handles positive and negative information in different hemispheres. Scientifically grounded research has found flattery, for example, is an emotion that human beings want and appreciate, not criticism, which is stressful, negative (Nass \& Yen, 2010). In The New York Times, Nass stated that human beings tend to see people who share negative information as smarter than those who share positive information (Tugend, 2012).

That is probably one of the reasons why fake news has leapfrogged into prominence among information consumers. Indian media mogul Rahul Roushan, founder of Faking News, a website that publishes satirical phony news on Indian politics and society can be credited for bringing this type of information to the limelight. The site occasionally publishes critiques of news from television stations.

Civic society has also weighed in on the moral value of fake news. Pope Francis has lamented the spread of false news, calling it "evil" and saying it leads to "arrogance and hatred." Based on other online press reports published between January and May 2018, the Pope has called on journalists and social media users to shun and unmask manipulative that foment division to serve political and economic interests, calling it 'satanic.' In a posting by Reuters, on Yahoo News January 31, 2018, the 
Pontiff said that "Fake news is a sign of intolerant and hypersensitive attitudes, and leads only to the spread of arrogance and hatred. That is the result of untruth." Then on February 26, 2018, CNN reporter Rosa Flores said that Pope Francis had likened fake news to 'crafty serpent' in the Book of Genesis. Media companies, community activists, influential local authorities, and country leaders should re-examine their conscience concerning the spread of fake news following the strong remarks of the most influential person in the world, the Pope.

\section{HOW ACADEMIA FOSTERS FALSE INFORMATION}

Hermeneutics is not immune to the blame associated with packaging and disseminating half-truths and information aimed at convincing a targeted audience. Text interpretation, especially the description of philosophical texts is not based on science but the reader's imagination and his/her understanding of related documents. In literature, for example, an analysis of a text is perceived as the truth and information from secondary sources known as literary critics that are by their right removed from the fact is used to support a perception or perceptions. The critic of a literary genre (e.g., fiction, poetry, prose) creates his/her own story from the original author's imagination-fantasy world. In that respect, writers and literary critics can be considered creators of fake news. By and large, the social sciences are involved in creating and sharing what we can find as 'false information,' because researchers pursue and use data to support their thesis, which is often regarded by other researchers as faulty. The fact that researchers focus on their own belief and collect data to help that belief opens the door for different views to be shared.

Even the hard sciences are not transparent when it comes to producing reliable data; they contribute their quota to the politicization of distorted information. Science is politicized when a company sponsors a scientist or research center to conduct research and produce data on its product to be shared with the company's potential audience. Scientists, science reporters, and politicians have warned that some individual scientists hold eccentric, subjective views. Dr. Victor Grech of the Department of Pediatrics at the Mater Dei Hospital in Malta has explained how science should be transparent in the advent of fake news. He states that the politicization of science for personal purposes, with the peddling of false news composed of the careful selection of facts that politicians wish to pursue and the data they are willing to promote or denigrate (2017). A Boston-based Science Correspondent for the Independent paper pens that science and its industry can make 'dangerous use of fake news and alternative facts' and warns people to become aware of 'fake news' or 'alternative facts' from big corporations and "eccentric" scientists - not just politicians and the media. For his part, Professor Kevin Elliott, philosopher specializing in the ethics of science advises people to trust the opinion of a major scientific organization, rather than read too much into a single piece of research. During a presentation at the American Association for the Advancement of Science's annual meeting in Boston in February 2017, Elliott said the public should find out if someone had a "significant vested interest that could skew their judgment" when reading about the latest supposedly stunning breakthrough (Johnston, 2017). We posit that sponsored research and programs often produce and disseminate results to other media audiences based on the objectives of the sponsor that may be biased and open to different interpretations.

International organizations that promote public and private enterprise have found misinformation on social media platforms as something that has positive and negative implications for their output. For example, the World Economic Forum in 2013 identified the spread of misinformation online as a significant risk in its Global Risks Report, but it was unable to determine steps to fix the problem.

\section{FAKE NEWS, POLITICS AND SOCIAL MOBILIZATION}

Some media think tank groups are making efforts to enlighten minority populations about the adverse effects of relying heavily on online news sources to obtain advice on businesses opportunities or learn about the world. Keeping it Real, a think tank group in Durham, NC, regularly has been explaining the impact of US government policy decisions and activities of major companies from online publications for over a decade. In a web posting in 2010 titled, BP "Oil Masters and the Art of masterful Deception," dealing with the oil spill in the Gulf of Mexico, the US Congress and US President reportedly failed to hold British Petroleum (BP) responsible. The writer warned Americans that the oil company BP functions as a sovereign government, contrary to the widespread view that it respects American laws (http://fahimknightsworld.blogspot.com ). By pointing out the lawmakers' laxity in sanctioning the petroleum company, the blogger suggested that minorities and people of 
good should have developed alternatives in dealing with dominant global political and economic players such as the US government and the British Petroleum company.

Hostile government actors have also been involved in generating and propagating fake news, particularly during elections (Merlo, 2017). Messages shared on some social networks about the ongoing Anglophone crises in Cameroon reveal that social media activists have been fanning the campaign against Presidential elections set to hold in October 2018, in retaliation, the government has planned to block internet supply to prevent citizens in favor of independence from being brainwashed by communications from the Diaspora. According to various YouTube postings and text messages on their I-phones, pro-independence activists have accused the government of Cameroon of maiming and killing unarmed independence seekers (civilians) while the government-owned television network, CRTV, has branded that the pro-independence groups as separatists and terrorists. This sort of propaganda by both sides makes it challenging to fact-check or persuade the entire public to determine the truth. However, the BBC and Aljazeera and other external news media are beginning to fact check the stories. It is difficult to assess the integrity of the message, however many people who received it believe it based on a straw poll conducted by this author.

Reports, particularly those broadcast through globally recognized cable news sources such as CNN, BBC, French, Chinese, and Russian news agencies and other media in large economies, show the potential consequences of the proliferation of cyber-mediated false news stories on global politics and partisanship. They also give users insight into how any information can easily persuade us to take action without remorse as long such information is delivered in a way that makes believe. Replication and repetition help give a perception of reality. Thus, re-publishing stories posted on unreliable networks such as Facebook and websites with no URLs, or sharing messages received from other networked communities contributes to the spread and believability of fake news.

There is scientific evidence of the influence of fake news sharing on social media on political outcomes. Viewers' access to fake news broadcasts can influence their decision-making and their attitudes of inefficacy, alienation, and cynicism toward the subjects covered. It can also serve as a moderator of the association of viewing hard news, fake news with their perceived realism as studies recently conducted in Israel and the United States have shown. Using survey data from the 2006 Israeli election campaign, Balmas (2014) has found evidence of an indirect positive effect of fake news viewing in fostering feelings of inefficacy, alienation, and cynicism, through the mediator variable of perceived realism of fake news (pp. 430-454). Other recent studies show that traditional activities understood to be in the domain of online privacy-sharing social media updates, commercial transactions, news gathering - can be reframed through the economic conceptions of labor and currency (Soto-Vásquez, 2017). Further, online survey responses from national samples in the US on voters' decision-making indicate that partisan identity and external political efficacy are not only positive predictors of third-person perception, but such perception leads to different ways of combating fake news online (Jang \& Kim, 2008). However, the actual effect of fake news on voters' decisions is still unknown, and concerns over the perceived effect of fake news online prevail in the US and other countries.

Take the case of a Southern Cameroonians that caught the world's attention in October 2016 when lawyers and teachers took to the streets to decry perceived economic injustice as well as cultural and linguistic discrimination. A year later, activists later created an interim government headed by a certain Julius Ayuk Tabe that started making plans to ensure total independence from the so-called Republic of Cameroon. A YouTube video posting with the headline, "Ayuk Tabe is not a terrorist," referring to the leader of English-speaking Cameroonians falsely accused of sponsoring militia groups to fight against the troops of the government of Cameroon - a country they are seeking independence from. The same video content has been interpreted as fake by anti-separation groups in the Frenchspeaking region in Cameroon. Further, there have been numerous postings on Youtube and other social media platforms from or about the 'interim government of the Federal Republic of Ambazonia' since the later declared its independence from Republique of Cameroun on October 1, 2017. The authenticity of the postings written and shared by pro-independence groups is hardly ever verified. However, it has become clear to most observers that interest in the burgeoining political crises has increased globally. Powerful countries, regional governing bodies (e.g., UNISA, African Union), international governing bodies (like the UN, UNHCR, Commonwealth of Nations); media agencies 
such as the BBC, France 24, VOA Africa, have called on both parties to dialogue and bring a lasting solution to the crises. It is also widely understood that messages, some unverified, provided to American lawmakers to seek solutions and to media agencies have come from social media platforms. Here, we see that news reporting on social media has significant implications for social mobilization, and that news content must not be truthful to persuade groups to take positive action. It should also be noted that Cameroon is one of Aljazeera's strongest communities online.

\section{FAKE NEWS AND SOCIAL RESPONSIBILITY}

We have to question whether communication scholars and media organizations were prepared for the unique digital media would play in denigrating our ethos - a practice that is characterized by fake news, digital overload, disinformation, propaganda, and immorality. We wonder whether it is not too late for the networked society to engage in responsible social media use. That statement begs the question for almost every I-phone or YouTube user has knowingly or inadvertently shared unverified content laden with inflammatory messages. Media experts, particularly news journalists, admit that news that deals with conflicts, disasters, and deaths sell papers. But if in their news coverage journalists do not strike a balance between the positive and negative reporting, they risk alienating a vital segment of the global audience. Journalists are required to be truthful in telling a story because they are considered as the first teachers in society, so they should avoid sourcing social media platforms to write stories. No matter the number of fake news consumers, traditional news organizations should note that their journalist integrity matters. Otherwise, any false information released that is promptly corrected could result in loss of respect, negatively affect public policy, and even lead an organization to make bad decisions, especially in developing nations where people get their news mainly from traditional media. Falsified information could cause some human casualties. The risks of believing fake news range from personal injury to national security. Thus, it is equally incumbent upon the media Facebook and I-pad owners to understand what constitutes false news if the risks of delivering and consuming such content outweigh the benefits.

\subsection{Fake News Reporting in Underdeveloped Nations}

Fake news reporting is an old phenomenon for African tabloid newspaper writers. The private press in financially strapped countries like Eritrea, Ghana, Cameroon, Nigeria, Chad, Niger, Mali, Cote d'Ivoire and Tunisia usually pick up stories from newswires and social media platforms and republish them without verifying their source because it lacks the resources to investigate information. Private newspapers disseminate information critical of the way the government manages its institutions, giving the general public a voice to comment on injustices in their country. In a bid to satisfy its readers and sustain its market, the private press ends up delivering misleading information to an unwitting national and international population. According to a press release posted by the Global Press journal on Nov 14, 2017, false rumors invaded social media several days before Zimbabwe's longtime president Robert Mugabe resigned. Bloggers had their version of the resignation. In fact, headlines flooded social media platforms such as 'The president is dead.' 'No, he was fired.' 'No, he resigned.' 'No, he is under house arrest.' The truth remained murky to most social media audiences for days, due in part to tight-lipped officials, but mostly to doctored photographs and forged documents invading social media. On WhatsApp and Facebook, the most popular social media platforms in Zimbabwe, some bloggers mentioned the country was under siege. Doctored photos of tanks rolling into Harare, the capital city, spread like wildfires during a harmattan. The public in Zimbabwe was interested mostly in learning about the incident from private news sources, not state-run media or any other channel.

\section{ANALYSIS OF LESSONS LEARNED}

Fake news is an acceptable source of public discourse that engages people. When unmonitored activities on social media platforms undermine fact-based reporting, we must expect media researchers to respond. If fake news reporting is unwarranted by the community, the question becomes one of content control - whether the media industry should be organized as a monopoly or a competition and who should have the right to monitor the information to be shared.

From another angle of our reading of the content above, we come away with the idea that fake news requires a greater inquiry by media students and faculty, policymakers grappling with questions of regulation and prevention, and those concerned about this unavoidable situation. 
We also note that (1) exciting news content can engage people of all socio-economic and backgrounds; (2) that potentially inflammatory news content creates new communities; (3) that the goal of inflammatory news content creators is to spread rumors on social media by monitoring conversational threads. We understand that people accept news content before its authenticity status is resolved. Hence the fabricated story pretending to be pure journalism is not likely to go away-the genre has rapidly become a means for writers to make money and potentially influence public discourse. Consequently, we find four emerging interlocking paradigms: fake news is per se the federal agency that brings people together, occupies their 'productive' time, gives them something else to think about as a group and act upon, and helps massage their emotions. Most important, fake news sharing is capable of advocating measurable positive change within the communities that use social media. In short, fake news is a necessary ingredient in the stewpot in our collective social life. Fake news can counteract the efforts of the politically fragile nations in the world that want to continue controlling news flow to suppress information that can cause public uprisings because it is created by anyone and shared on personal media platforms.

\subsection{Implications of False Information Sharing for Nation Building}

Fake news is necessary for forecasting revenue and post-truth politics for media outlets because they spend much time commenting on its components, thereby attracting viewers to their websites, a great ploy to broaden participation, viewership, and discourse and generate broadcast and online advertising revenue. Research shows that easy access to online advertisement revenue increased political polarization, and the popularity of social media, primarily the Facebook News Feed are implicated in the spread of fake news (Hunt, 2016; Woolf, 2016). Publishing a story with false content on a commercial media platform attracts readers, and this eventually benefits advertisers and ratings. Thus, advertising has a real opportunity to state its case in a forceful, direct and compelling way so there will be no doubt what the product represents. But as blogger Rance Crain (2017) has stated in a blog at AdAge, advertisers would lose the opportunity if they end up supporting fake news because they cannot control where their digital ads run. Fake-news sites are using disinformation to pull in big audiences and significant ad revenue in turn.

We further contend that the act of believing in the news is a matter of custom or character, and each nation must see a fake story based on its perception, culture, or reality. This position is grounded on the premise that morals involve developing, defending, and recommending concepts of right and wrong behavior. However, these concepts do not change as one's desires, and motivations vary. Thus a nation can utilize fake news reports to evaluate its population's interest or make plans for its educational, cultural and economic advancement. Fake news can help construct specific business sectors of the nation and still keep the universally approved journalistic standards that include the free exchange of information that is accurate, fair and thoroughly researched.

The ongoing demand for alternative facts has moved the yardstick for measuring the consumer-driven economy, and advertising seems to be leading the way. The ability for I-pads and I-phones to carry online content gives consumers more knowledge about market products and services, which helps them make decisions. For their part, media advertising companies have succeeded in unearthing financial benefits of marketing inaccurate news to targeted audiences. For example, seventy-one percent of people in the United Kingdom connect advertising with fake news. Research commissioned by Rakuten Marketing reveals that Brits lead the way when it comes to campaign skepticism in comparison with Europe and the US, where the comparative figures sit at 54\% and 58\% respectively. Some observers have even claimed that fake news makes advertising more believable. It appears that certain nations enjoy financial benefits when false stories disseminated. In the United States, for example, where without prior thorough investigation has become a significant mechanism for generating revenue among media companies and has increased fierce competition for consumers' attention and their money. In an article posted at the Daily Grill January 29, 2018, at www.dailygrail.com, blogger Fahim A. Knight-El, wrote:

The news networks, particularly television stations in the United States have lowered their newsgathering and packaging standards, and resorted to using clandestine methods of reporting to attract viewers. Traditional media outlets that are warring to present breaking stories and capitalizing on national and global audiences before anyone else, but social media is covertly driving mainstream media to this end (Knight-El, 2018). 
Worse, daily and weekday newspaper circulation has plummeted from 62 million to an estimated 35 million over a span of 26 years, as $93 \%$ of adults in the U.S. have turned to getting their news online through mobile devices or desktops (Loechner, 2018). This trend may be leveraging tremendous pressure on journalists to work expeditiously to get to the reporting finish line first, using every means at their disposal.

Further to the fear that fake news reporting could be diminishing journalistic standards and profitfocused based information sharing phenomenon in the media industry is the growing trend among state governments in shaping media policies to meet market demands, especially the information demand-supply chain. Faced with increasing information flows within their national borders, information ministers, senators, even heads-of-state are advocating the design or amendment of their information and communication policies to meet the demands of the growing IT market, at the expense of good journalistic ethics, and promoting the fake news reporting agenda. Concern about misinformation on social media has led Facebook and Google to announce plans to crack down on fake news sites, restricting their ability to garner ad revenue. Perhaps that could limit the amount of malarkey online even though news consumers themselves are the best defense against the spread of misinformation.

Another problem on social media is that people validate information by forwarding it to others without vetting. Validation of false news propaganda occurs when influential public figures weigh in on the subject. For example, since he became the United States President, Donald Trump has lambasted U.S news outlets for reporting "fake news" on his tweeter account, thereby fostering speculation that Russia had meddled in the US presidential election from which he emerged the winner (https://www.dailygrail.com/blog/fake-news). Through various media outlets, political scientists and leaders of democratic nations have decried the misuse of media platforms by elected public officials to spread false information to the masses. In an eye-opening article written on how to Spot Fake News Eugene Kiely and Lori Robertson (2016) FactCheck.org, a project of The Annenberg Public Policy Center, argue that some the misinformation shared online is complete fiction.

\subsection{Engaging Socially-Mediated Messages for Nation-Building}

Although more citizens in developing states are relying on the private press for news about social and economic matters than state-run media known for promoting government propaganda, this phenomenon is likely to change in next few years for a number reasons. First, from socio-economic perspective handheld devices are affordable and are being used by more people. I-phones are being mass produced, are cheaper and compatible with local telephone towers. Refurbished I-phones and affordable ones imported from China, the UAE and Dubai are in demand in the towns and cities. Further, there is broad interest among the youth in using social media products which make up over $75 \%$ of Africa's population.

The youth in fragile states depend on social media, and development institutions have found some success in engaging the youth with messages geared for social change (Fayoyin, 2015).

Other reasons to engage social media in the advancement of nation building are that (1) reporters in fragile states do not have adequate resources to verify news sources, (2) there is fierce competition among the private newspapers to publish breaking news, so they rush to print the papers. (3) Specific zones are insecure and dangerous-- too risky for journalists. (4) Government officials punish journalists who criticize the government. They shut the business, imprison journalists, or cut funding, so some papers resort to providing favorable coverage to escape from those repressive actions. (5) Some reporters do not have adequate training in storytelling, including data collection and interviewing techniques.

\subsection{Nation-Building Techniques: Using Social Media and Traditional Media Reporting as Supplements}

More citizens are getting news from the private press because they find news produced by government-run press fake, less worthy or limited regarding the quality. To estimate the value of news flow in shaping community wellbeing and decision making in developing states, we must identify who indeed owns or controls the media. Three World Bank authors and the highly regarded RussianAmerican Harvard-based economist Andrei Shleifer have closely examined patterns of media 
ownership. They have found that in most countries around the world, the largest media firms are owned by the government and property is more pervasive in broadcasting than in the printed media. Professor Shleifer, Simeon Djankov, Caralee McLeish and Tatiana Nenova (2003) found that media firms in 97 countries have ownership structures with shareholders who are families or governments countries that are poorer, more autocratic, with lower levels of primary school enrollment, and higher levels of state intervention in the economy (p. 373). As part of their development agenda, many new nation-states have been investing in public information management, mainly the programming and delivery of news across the nation after the United States began privatizing Internet operations in 1995. While some governments purchased computers and related IT tools to facilitate data storage and improve learning in schools, others used the technology to monitor free speech in the country.

The informed public observers have roundly condemned the way governments have applied modern information and communication technology in their respective nations to bring social change. Communication for change researchers invariably criticize them for stunting freedom of expression in the media and slowing development at the national level (Ainselie, 1966; Babatunde, 1975; Bourgault, 1996; Ngwainmbi, 1994, 2014). As more social media platforms become available to the citizens, they will likely seek other avenues to exercise their right to free speech and willingness to receive and share any type of information. It should be noted that the young people in the world's most press repressive regimes such as Eritrea, Syria, Iran, China, Cuba share information on Facebook and I-phones critical of their government. Some have been organizing rallies and advocating for immediate reform on those platforms, yet the government security forces have not succeeded in suppressing such activities, according to media reports.

In some cases, however, the advocates tend to report erroneous information about government operations forcing officials to issue press releases, or speak on television to correct the information. Those approaches are designed to ensure information control by the state-sponsored media, but they seem to backfire as social media influencers usually spread their version on social media before the news anchors air the story.

There exists a fair amount of moral panic in the professional African media and sociopolitical communities that have created a backdrop for debates about the real impact of fabricated news on national politics and governance in Africa. The problem seems so severe that some news agencies have taken steps to educate the public about the potential effects of fake consumption on democratization. In December 2017, Eye Witness News (EWN) a South African television news network published a manual for dealing with false news online amid allegations that the governing African National Congress (ANC) had planned to run a campaign to create and disseminate false information to discredit opponents ahead of the local election. EWN placed a bold alert, FAKE! on stories posted online whose content could not be verified. The news network also provided a link to another page with tips on how to spot fake news, and a list of websites it had identified as purveyors of false reports. The publication also invited readers to submit any false news they come across and stories they are unsure about (Olewe, 2017). In another bid to control fake news proliferation online, the world renown British Broadcast Corporation (BBC) website republished an article warning readers not to read a story about Eritrean men posted on the BBC portal. The word FAKE (in red) superimposed over the body of the article (http://www.bbc.com/news/world-africa-38883347).

\subsection{Techniques for Using Fake News Platforms to Foster National Development}

The quest for a system to initiate the creation of false news often collides with basic principles of democratic values like freedom of expression. However, we can see the sharing of false information as a cohesive force - a means of keeping people engaged in a conversation, a discourse over its potential short-to medium-term value or uselessness. The fake news gives people something else to talk about. Global multimedia technology companies such as Yahoo, Google, Facebook, and Apple should take immediate stringent measures to combat the proliferation of fake news on social media platforms because it mostly misinforms and misdirects the innocent news consumers who lack appropriate tools to identify it and are overwhelmed by its constant presence. Google can be applauded for taking the fight against false news sharing to a new level by announcing initiatives aimed at combating the spread of misinformation on the internet. For instance, Google invested $\$ 300$ million from 2018-2021 to support real journalistic news reporting and limit fake news (de Looper, 
2018). By collaborating with the news industry to surface accurate information and sponsoring an International Fact Check Network to track and suppress misinformation when news breaks on Facebook, Google would be contributing hugely to good journalistic practice globally.

Sharing fake news can help reduce stress. In industrialized, mechanized open societies like the US, Germany, France, Japan and the UK where suicide rates are high, where people keep long work hours, and the cost of living continues to increase, fake news sharing on all media platforms should be encouraged. On the contrary, pure news reports bring sad feelings. Tragedies, conflicts, and health and economic crises get all the attention in the media, but such information has long-term adverse psychological effects on the audience. Thankfully, billions of people are using social media every day. With an estimated 2.44 billion people currently using social media platforms for personal relationships, entertainment, at work and in studies, there is a potential for messages to be distributed on this platform to package messages or even use the fake news audience to develop a new business model.

Infotainment, a characteristic of fake news, can be useful for democracy in that only a minority of news audiences follow the hard news. Conversely, social media platforms provide a forum for free expression. For example, with a small amount of money, political activists can own a channel on YouTube where they post their views about the government, public figure or any other trending topic they may like or dislike.

Misinformation can influence our behaviors on a massive scale. Hence, lawmakers, social science researchers, behavior change experts and social welfare sectors in the government should invest resources to understand how it works and what must be done to mitigate its harmful effects on the sociopolitical and economic advancement of the nation.

Finally, the lessons learned from mistakes such as heavy reliance on the fake news could in due course be assessed to find new ways of dealing with it in the future if the nation's lawmakers and their people jointly determine that fake news is detrimental to the nation's growth. Otherwise, variations of false news reporting should be encouraged by the people and their lawmakers if they find phony news useful in fostering a national spirit.

\section{REFERENCES}

[1] Ainselie, Rosalynde. (1966). The Press in Africa. London: Victor Gollancz, Ltd.

[2] Allcott, Hunt; Gentzkow, Matthew. (2017) Social Media and Fake News in the 2016 Election. Working paper for the National Bureau of Economic Research, No. 23089.

[3] Anderson, A. J. (1988) Mediated Communication: A Social Action Perspective. CA: Sage

[4] Atkinson, R. (Jan. 20, 2017) Fact or Fiction: How Fake News Became So Popular. https://ashleyr oseatkinson. wordpress.com Retrieved Feb. 18, 2018

[5] Babatunde, Jose. ) 1975). Press freedom in Africa. African Affairs, 74: 255-62.

[6] Balmas, Meital (2014) When Fake News Becomes Real. Communication Research, 41 3, pp.430-454

[7] Baudrillard, J. (1981) Simulacres et Simulation, Éditions Galilée, Paris, 1981.

[8] Bourgault, Louis (1996) Press Freedom in Africa: A Cultural Analysis. Journal of Communication Inquiry, 17, 2, 69-92.

[9] Brinkley, A. (1999) Culture and Politics in the Great Depression. Markham Press Fund

[10] Castells, M. (2004) Informationalism, Networks, and the Network: A Theoretical Blueprint. In Manuel Castells (Ed.) The network society: a cross-cultural perspective, Northampton, MA: Edward Elgar.

[11] Castells, M. (November 2010) Globalization, Networking, Urbanization: Reflections on the Spatial Dynamics of the Information Age. Urban Studies, 47, 13, 2737-2745.

[12] Collier, Graham (April 2013) Escapism, and Contemporary Life. Psychology Today. https://www. psychology today.com/blog/the-consciousness-question/201310/escapism-and-contemporary-life

[13] Combating Fake News: An Agenda for Research and Action. Shorenstein Center on Media, Politics and Public Policy https://shorensteincenter.org/combating-fake-news-agenda-for-research/ Posted May 2, 2017.

[14] Crain, Rance (February 06, 2017) How Fake News Could Make Advertising more believable. http://adage .com.Retrieved May 22, 2018. http://adage.com/article/rance-crain/fake-news-make-advertising-believable 1307836/

[15] De Fleur, Melvin \& Ball-Rokeach, Sandra J. (1989). Theories of Mass Communication. New York: Longman. 
[16] De Keersmaecker?, Arne Roets (2017) 'Fake news': Incorrect, but hard to correct. The role of cognitive ability on the impact of false information on social impressions. Intelligence, 65, 107-111. http://dx.doi.org/10.1016/ j.intell.2017.10.005

[17] De Looper, C. (March 2016). The Google News Initiative aims to step up the fight against fake news. Digital Trends. https://finance.yahoo.com/news/google-news-initiative-aims-step-200558409 .html

[18] Deery, June (2012) Consuming reality: The commercialization of factual entertainment. New York: Palgrave Macmillan

[19] Djankov, S., McLeish, C., Nenova, T. \& Shleifer, A. (October 2003) Who Owns the Media. Journal of Law and Economics, 46, 2, 341-381.

[20] Eugene Kiely and Lori Robertson (posted November 18, 2016) How to Spot Fake News https://www.factcheck. org/2016/11/how-to-spot-fake-news.

[21] "Fake news busters." POLITICO. 2017-09-14. Retrieved 2017-09-15.

[22] Farsetta, Diane, and Price, Daniel (April 6, 2016) Fake TV News: Widespread and Undisclosed. https://www.prwatch.org/fakenews/execsummary

[23] Fayoyin, Adebayo (2015) Positioning Youth Development Agenda in Public Discourse in Nigeria: An Advocacy Imperative. Open Access Library Journal, 2: e1875.

[24] Johnston, Ian (February 19, 2017) Science can make dangerous use of fake news and alternative facts. Independent. https://www.independent.co.uk Retrieved May 17, 2017.

[25] How fake news becomes a favorite, trending topic - CBS News https://www.cbsnews.com/news/how-fakenews-find-your-social-media-feeds/ retrieved Feb. 6, 2018.

[26] Hunt, Elle (December 17, 2016). "What is fake news? How to spot it and what you can do to stop it". The Guardian. Retrieved January 15, 2017.

[27] Grech, Victor (2017) Fake news and post-truth pronouncements in general and in early human Development. Early Human Development, 115, 118-120.

[28] Jang, S. Mo \& Kim, Joon K. (2008) Third-person effects of fake news : Fake news regulation and media literacy interventions. Computers in Human Behavior, 80, pp.295-302

[29] Gudipaty, Nagamallika (2017) Television, Political Imagery, and Elections in India. In Emmanuel K. Ngwainmbi (Ed.) Citizenship, Democracies, and Media Engagement among Emerging Economies and Marginalized Communities. New York, NY: Palgrave Macmillan. Pp. 117-145

[30] Knight, -El, Fahim (January 29, 2018) Fake News, what is the Global Implication; what is the Price? https://www.dailygrail.com/blog. Accessed February 12, 2018.

[31] Leonhardt, David; Thompson, Stuart A. (June 23, 2017). "Trump's Lies." The New York Times. Retrieved Feb 18, 2018

[32] Loechner, J. (2018) "Fake News" Possible Benefit. https://www.mediapost.com Retrieved Feb. 13.

[33] Lim, Merlyna (2017). Freedom to hate: social media, algorithmic enclaves, and the rise of tribal nationalism in Indonesia. Journal of Critical Asian Studies, 3, 49, 411-427.

[34] Lloyd, John (February 6, 2017) Commentary: Trump tweets show how social media can hurt democracy http://uk.reuters.com/article/us-100days-lloyd-commentary/commentary-trump-tweets-show-how-socialmedia-can-hurt-democracy-idUKKBN15I214

[35] Merlo, Carlo (2017), "Millonario Negocio FAKE NEWS," Univision Noticias.

[36] Masiyiwa G. and Mujuru, Linda (Nov 23, 2017) Political Chaos Reveals Abundance of Fake News on Zimbabwe Social Media. The Global Press Journal. Retrieved Feb. 9, 2018.

[37] Nadel, Alan. (1996) Television in Black-and-White: Race and National Identity. Lawrence, KS: University Press of Kansas.

[38] Nass, Clifford \& Yen, and Corina (2010) The Man who lied to his laptop: What machines teach us about human relationships? New York, NY: Penguin.

[39] Ngwainmbi, k. Emmanuel (1994) Communication efficiency and rural development in Africa: The Case of Cameroon. Lanham, MD: University Press of America

[40] Ngwainmbi, K. Emmanuel (July 2014) Media, and Translation-An Interdisciplinary Approach International Journal of Communication, 8. Review.

[41] Olewe, Dickens (February 16, 2017) Fake news: How can African media deal with the problem? www/bbc.com/Africa Retrieved Feb. 6, 2018.

[42] Ordway, Denise-Marie (2018) Fake news and the spread of misinformation. https://journalistsresource.org/ studies/society/internet/fake-news-conspiracy-theories-journalism-research Retrieved Feb. 6, 2018 
[43] Pathunkkala, S. (2017) The Changing Face of Television and Public Policy Implications in India. In E. Ngwainmbi (Ed.) Citizenship, Democracies, and Media Engagement among Emerging Economies and Marginalized Communities. New York, NY: Palgrave MacMillan, pp. 103-116

[44] Schlesinger, Robert (April 14, 2017). "Fake News in Reality." U.S. News \& World Report.

[45] Shipley, A. T. (2003) The Road to Middle-Earth: How J.R.R. Tolkien Created a New Mythology. Boston: Houghton-Mifflin

[46] Soto-Vásquez, Arthur D. 2017. Reconceptualizing Digital Privacy: Examining Two Alternatives in the 2016 Presidential Election. The Journal of Communication and Media Studies 2 (2): 33-45. doi:10.18848/2470-9247/CGP/v02i02/33-45.

[47] Southwell, B., Thorson, E. \& Sheble, L. (Eds.) (2018) Misinformation and Mass Audiences. Austin, University of Texas.

[48] The Coin Telegraph. Big brands are now using block chain to fight ad fraud and fake views. https://thenextweb.com Accessed February 16, 2018

[49] Tugend, Alina (March 2012) Praise is fleeting, but Brickbats we recall. The New York Times. www.nytimes.com Retrieved Jan. 27, 2018.

[50] Wardle, C (2017) Fake news. It's complicated. First draft news, https://firstdraftnews.Com/fake-newscomplicated/, (2017), Accessed Aug 25, 2017.

[51] Woolf, Nicky (November 11, 2016). "How to solve Facebook's fake news problem: experts pitch their ideas." The Guardian. Retrieved January 15, 2017.

[52] Zubiaga, Arkaitz; et al. (2016) Analyzing How People Orient and Spread Rumors in Social Media by Looking at Conversational Threads doi: 10.1371/journal.pone.0150989.

Citation: Emmanuel K. Ngwainmbi. "Why Follow All the Hoopla? Fake News Reporting on Social Media Platforms and Implications for Nation-State Building". International Journal of Media, Journalism and Mass Communications (IJMJMC), vol 4, no. 2, 2018, pp. 29-43. doi:http://dx.doi.org/10. 20431/2455-0043.0402004

Copyright: (C) 2018 Authors. This is an open-access article distributed under the terms of the Creative Commons Attribution License, which permits unrestricted use, distribution, and reproduction in any medium, provided the original author and source are credited. 